\title{
Equilibrium oxygen- and hydrogen-isotope fractionation between ice and water
}

\author{
M. Lehmann and U. SiegenthaleR \\ Physikalisches Institut, Universität Bern, CH-3012 Bern, Switzerland
}

\begin{abstract}
We have performed high-precision measurements of the isotopefractionation factors between ice and water. Ice was grown from a stirred water mass on a cooling plate. The freezing velocity was varied, keeping the stirring rate of the water constant, so that the equilibrium fractionation factors could be
\end{abstract} determined by extrapolating to zero freezing velocity. The resulting values are

$$
\begin{gathered}
\alpha\left({ }^{18} \mathrm{O} /{ }^{16} \mathrm{O}\right)=1.00291 \pm 0.00003 \text { and } \\
\alpha(\mathrm{D} / \mathrm{H})=1.0212 \pm 0.0004 .
\end{gathered}
$$

Non-equilibrium freezing of lake and sea ice is briefly discussed as well as the significance of our results for the deuterium excess in polar precipitation.

\section{INTRODUCTION}

For modelling isotopic processes in the global water cycle, fractionation factors have to be known. The ${ }^{18} \mathrm{O} /{ }^{16} \mathrm{O}$ fractionation factor between ice and water is not precisely known from work published so far. We report here on experimental results for the fractionation between ice and water in ${ }^{18} \mathrm{O} /{ }^{16} \mathrm{O}$ and $\mathrm{D} / \mathrm{H}$. Our aim was to obtain high accuracy and especially to find the values at equilibrium. The latter aim was achieved by controlling the degree of disequilibrium and extrapolating to equilibrium. This also yielded instructive results for studying the influence of disequilibrium under natural conditions.

\section{EXPERIMENTAL METHOD}

The method we used was to grow ice from water of known isotope composition. Ice is produced in isotopic equilibrium with the bulk of the water only if the freezing velocity is very small compared to the mixing rate of the water, because otherwise an isotopic gradient is established in the water near the interface. Because it is not possible to determine a priori under what conditions this gradient is negligible, we controlled carefully the freezing velocity and varied it between different experiments, so that we could then determine the equilibrium by extrapolating the results to zero freezing rate.

The apparatus we used (Fig. 1) consists of a Plexiglas cylinder (inner diameter $9.0 \mathrm{~cm}$, free inner height $15.5 \mathrm{~cm}$ ) mounted water-tight on a cooling plate cooled by a Peltier element (Peltron PKE 36; maximum cooling power $20 \mathrm{~W}$ ). The cover has a (controlable) motor for the propeller stirring the water, and a probe for measuring the water temperature can be inserted through a hole in the cover. This hole also allows some air exchange, which

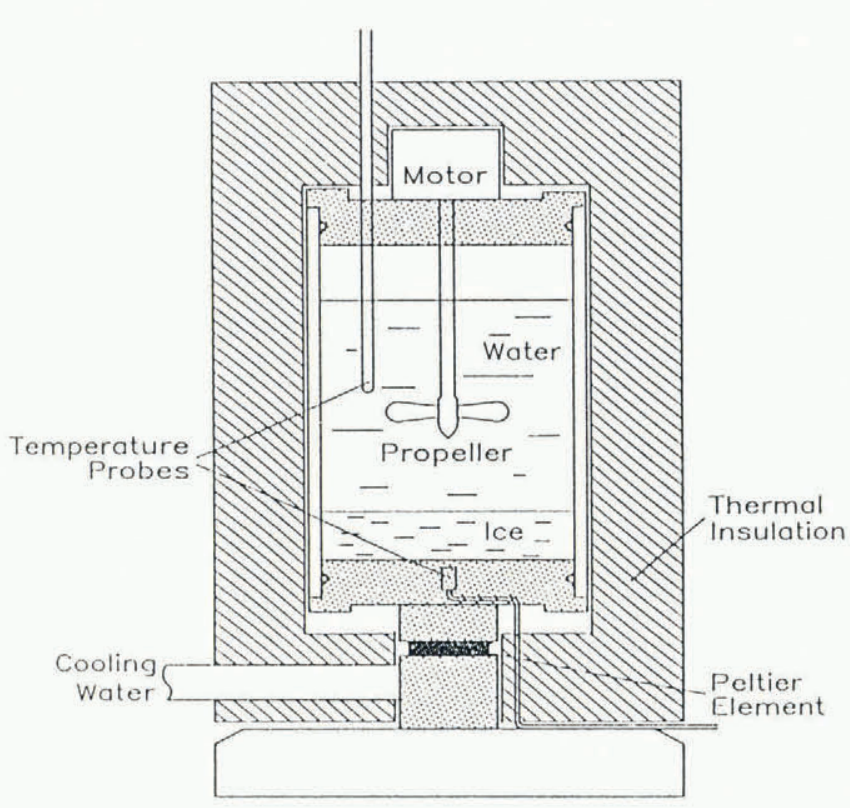

Fig. 1. Apparatus used for measuring isotopic fractionation between water and ice.

is necessary to avoid over-pressure in the cylinder when the water freezes. The whole apparatus is well insulated thermally by means of styrofoam.

For an experiment, c. $800 \mathrm{ml}$ water of known isotopic composition were poured into the cylinder, leaving an air space above the water in order to avoid overflow in consequence of the expansion during freezing. After the water had cooled down to $0^{\circ} \mathrm{C}$, freezing was initiated by adding very small pieces of ice (total mass $<0.03 \mathrm{~g}$ ) in order to avoid supercooling and an irregular onset of ice growth. The water was stirred by means of a propeller, 
the revolution rate of which was held constant at about $17 \mathrm{rev} \mathrm{min}^{-1}$ for all experiments.

The freezing rate was determined by measuring the ice thickness, usually at ice increments of about $0.5 \mathrm{~mm}$, through a side window in the thermal insulation. For some experiments, the freezing velocity was kept constant. This could be achieved approximately by regulating the current of the Peltier element such that the water temperature was constant at about $0.3^{\circ} \mathrm{C}$; when necessary, the current was corrected manually. The experiment was stopped when the desired ice thickness, between 10 and $80 \mathrm{~mm}$, was reached, typically after several hours. Water samples for isotopic analysis were taken at the end of the experiment, and, by means of a syringe through a hole in the cover, during the experiment. The ice block was taken out of the Plexiglas cylinder and cut with a hot-wire saw, which proved to be considerably better than a band saw regarding precise, plane surfaces and small loss of ice during cutting. A lateral sample, representing the average composition, was taken from the ice cylinder; the rest was cut into parallel slices representing different stages of the ice growth.

${ }^{18} \mathrm{O} /{ }^{16} \mathrm{O}$ and $\mathrm{D} / \mathrm{H}$ ratios were determined by mass spectrometry. ${ }^{18} \mathrm{O} /{ }^{16} \mathrm{O}$ was measured in our laboratory, and $\mathrm{D} / \mathrm{H}$ at the Institute for Environmental Physics, University of Heidelberg. Analytical precision $(1 \sigma)$ is $\pm 0.03 \%$ and $\pm 0.5 \%$, respectively.

In an experiment, we controlled whether the ice composition was horizontally homogeneous and found a slight $\left(0.1^{\circ} \%\right) \delta^{18} \mathrm{O}$ increase from the center towards the periphery of the ice cylinder, which should have negligible influence.

\section{EVALUATION OF DATA}

If the freezing rate is not negligibly small compared to the mixing rate of the water, an isotopic gradient will be established in the water near the interface (Fig. 2), so

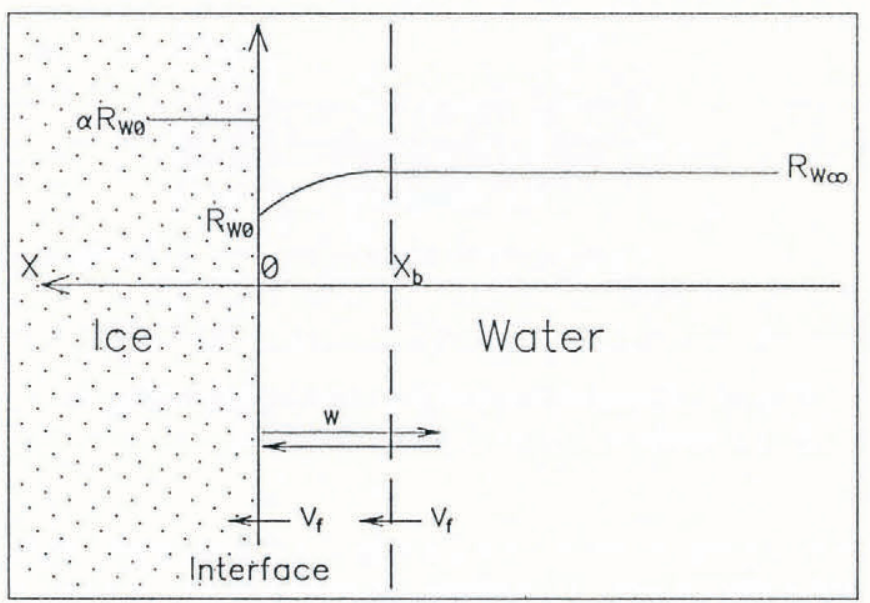

Fig. 2. Schematic distribution of the isotopic ratio $R\left({ }^{18} \mathrm{O} /{ }^{16} \mathrm{O}\right.$ or $\left.\mathrm{D} / \mathrm{H}\right)$ in water and ice near the common interface. An isotopic gradient exists near the interface in a boundary layer $\left(x=0\right.$ to $\left.x=x_{b}\right)$; for $x>x_{b}$, the water is assumed to be well mixed. $v_{f}$ is the freezing velocity; $w$ denotes the transfer coefficient (transfer velocity) for mixing. that the ice is not in isotopic equilibrium with the bulk of the water (assumed well mixed). At steady state, the isotopic composition of the water transported in net from the right into the boundary layer at $x=x_{\mathrm{b}}$ (cf. Fig. 2) must be equal to that of the water leaving at the left by freezing, which gives, in a reference frame fixed to the ice-water interface ( $x=0$, fluxes positive to the left):

$$
w\left(R_{\mathrm{w} \infty}-2 R_{\mathrm{w} 0}\right)+v_{\mathrm{f}} R_{\mathrm{w} \infty}=v_{\mathrm{f}} \alpha R_{w 0}
$$

where $R_{\mathrm{w} \infty}, R_{\mathrm{w} 0}$ is the isotopic ratio of bulk water and water at the interface, $v_{\mathrm{f}}$ is the freezing velocity, and $w$ is the transfer velocity for mixing between $x=0$ and $x=x_{\mathrm{b}}$. For the concept of transfer velocity (or transfer coefficient), see e.g. Danckwerts (1970).

If we define an apparent fractionation factor by

$$
\alpha_{\text {app }}=\frac{\text { isotope ratio of newly formed ice }}{\text { isotope ratio of bulk water }}=\alpha \frac{R_{\mathrm{w} 0}}{R_{\mathrm{w} \infty}}
$$

we find from Equation (1):

$$
\alpha_{\mathrm{app}}=\alpha\left(1-\frac{(\alpha-1)}{1+\alpha\left(v_{\mathrm{f}} / w\right) \cdot\left(v_{\mathrm{f}} / w\right)}\right)
$$

or, denoting $\epsilon=\alpha-1$ as fractionation constant:

$$
\epsilon_{\mathrm{app}}=\epsilon\left(1-\frac{v_{\mathrm{f}} / w}{1+\alpha\left(v_{\mathrm{f}} / w\right)}\right) .
$$

For sufficiently small freezing velocity, $v_{\mathrm{f}} \ll w$, this can be simplified to

$$
\epsilon_{\mathrm{app}} \approx \epsilon\left(1-\alpha\left(v_{\mathrm{f}} / w\right)\right) \approx \epsilon\left(1-\left(v_{\mathrm{f}} / w\right)\right),
$$

that is, the apparent fractionation (which we directly determine from the experiment) is a linear function of the freezing velocity $v_{\mathrm{f}}$. The second equality is obtained when noting that $\alpha \approx 1$. It is not possible to say a priori how the transfer velocity for mixing, $w$, depends on the stirring rate, so we kept the stirring rate constant for all experiments. Before calculating fractionation factors, we optimized the experimental results by a least-squares method (Stiefel, 1976), making use of the fact that the isotopic compositions are over-determined by the isotope balance between initial state (water) and final state (ice plus water).

The isotopic composition of the ice varies during freezing according to a Rayleigh process, provided $\alpha_{\text {app }}$ is constant, and is therefore given by (see e.g. Gat, 1980)

$$
1+\delta_{\mathrm{i}}=\alpha_{\mathrm{app}}\left(1+\delta_{\mathrm{w} 0}\right) f^{\alpha_{\mathrm{app}}{ }^{-1}}
$$

where $f$ is the remaining (not yet frozen) fraction of water and $\delta_{\mathrm{w} 0}$ is the value for the bulk water for $f=1$. We have evaluated $\alpha_{\text {app }}$ for single ice layers, by integrating Equation (5) over the appropriate $f$ interval (setting $f=1$ at the beginning of the ice layer) and interpolating $\delta_{\mathrm{w} 0}$ from the intermediate water samples.

\section{RESULTS}

Figure 3 shows the resulting apparent fractionation con- 

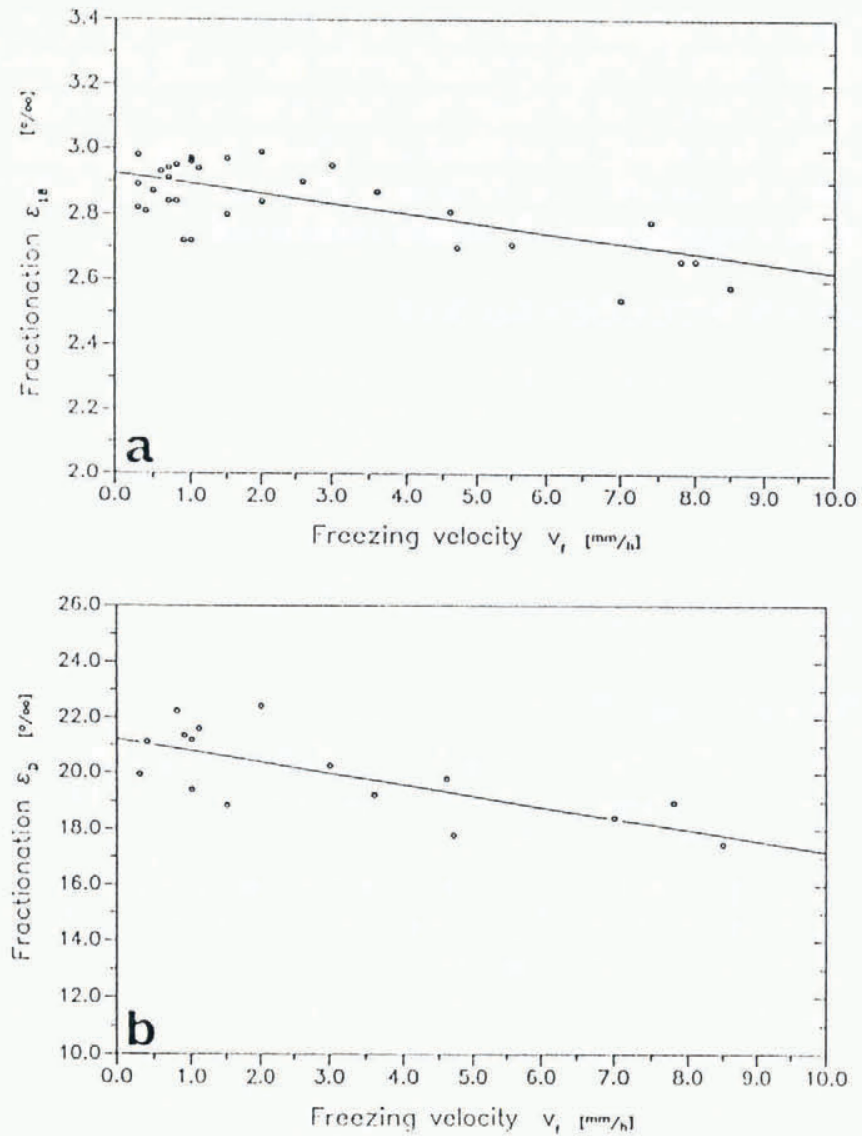

Fig. 3. Experimental results for the apparent fractionation constant $\epsilon_{a p p}=\alpha_{a p p}-1$, as a function of the freezing velocity, for ${ }^{18} \mathrm{O} /{ }^{16} \mathrm{O}$ (top) and $\mathrm{D} / \mathrm{H}$ (bottom). Also shown are regression lines through the experimental results.

stants $\epsilon_{\text {app }}$ as a function of the freczing velocity $v_{\mathrm{f}}$; in addition, a least-squares-fit line, corresponding to the expected linear relation (4), is shown. The error of the individual results is of the order of $0.1 \%$ for $\epsilon_{18}$ and $1 \%$ for $\epsilon_{\mathrm{D}}$. The equilibrium fractionation constants $\epsilon=\alpha-1$, obtained from the regression lines at $v_{\mathrm{f}}=0$, are

$$
\begin{aligned}
& \epsilon_{18}=2.91 \pm 0.03 \% \\
& \epsilon_{\mathrm{D}}=21.2 \pm 0.4 \% .
\end{aligned}
$$

From the slope of the regression lines in Figure 3, we obtain the transfer velocity $w=97 \pm 33 \mathrm{~mm} \mathrm{~h}^{-1}=$ $(2.7 \pm 0.9) \times 10^{-5} \mathrm{~m} \mathrm{~s}^{-1}$; this characterizes the water mixing rate for the propeller speed we had chosen for our experiments. Our maximum freezing velocities were about $9 \mathrm{~mm} \mathrm{~h}^{-1}$, so that $v_{\mathrm{f} / \mathrm{w}} \approx 0.1$ and Equation (4) is still a good approximation to Equation (3). According to Danckwerts' (1970) surface renewal model, $w$ is related to the mean renewal rate $s$ of the water parcels at the ice-water interface by $w=(\mathrm{D} k)^{\frac{1}{2}}$. With the diffusion coefficient for water at $0^{\circ} \mathrm{C}, \mathrm{D}=1 \times 10^{-9} \mathrm{~m}^{2} \mathrm{~s}^{-1}$; this yields $k=0.7 \mathrm{~s}^{-1}$, or a mean residence time $k^{-1}$ of a water parcel at the interface of $1.4 \mathrm{~s}$.

In a $\delta \mathrm{D}-\delta^{18} \mathrm{O}$ plot, the ice compositions are expected to lie on a line given by

$$
(1+\delta \mathrm{D}) /\left(1+\delta \mathrm{D}_{0}\right)=\left[\left(1+\delta^{18} \mathrm{O}\right) /\left(1+\delta^{18} \mathrm{O}_{0}\right)\right] S
$$

where $S=\epsilon_{\mathrm{D}} / \epsilon_{18}$, which is approximated very well by a straight line with slope $S$ as long as the occurring $\delta$ values are not too negative, i.e. the remaining fraction of the water is not very small. (This can be seen by considering the Rayleigh formulae, Equation (5), for D and ${ }^{18} \mathrm{O}$ and eliminating $f$.) From our results, Equation (6), $S=7.29 \pm 0.16$. Direct comparison of the $\delta \mathrm{D}$ and $\delta^{18} \mathrm{O}$ values of our water and ice samples on such a plot indeed shows the expected linear relation, which strengthens the confidence in the overall procedure used.

\section{COMPARISON WITH OTHER WORK}

Experimental results of other authors for the fractionation constants are compiled in Table 1 . None of the directly determined $\epsilon$ values is significantly higher than

Table 1. Ice-water fractionation constants $\varepsilon=\alpha-1$ (in permil) for pure water. "Direct" and "indirect" refer to experimental determinations; "indirect" values are calculated from $\alpha$ (ice-vapour) and $\alpha$ (water-vapour) using Equation (7)

\section{Author Method Fractionation constant $\varepsilon$}

\begin{tabular}{|c|c|c|c|}
\hline $\begin{array}{l}\text { Posey and Smith } \\
\text { (1957) }\end{array}$ & Direct & & $21.1 \pm 0.7$ \\
\hline O’Neil (1968) & Direct & $3.0 \pm 0.1$ & $18.7 \pm 0.9$ \\
\hline Arnason (1969) & Direct & & $20.8 \pm 0.7$ \\
\hline
\end{tabular}

$\%$

\section{${ }^{18} \mathrm{O} \quad$ Deuterium}

Beck and Münnich Direct 2.87

(personal commun-

ication, 1988)

This work

Direct

$2.91 \pm 0.0321 .2 \pm 0.4$
Merlivat and Nief* Indirect* (1967), Majoube (1971b)
Majoube (1971a,b) Indirect ${ }^{\dagger}$
$3.4 \pm 0.3$

Theoretical (see text)

*Calculated from measured $\alpha_{\mathrm{SV}}=1.1330$ (revised evaluation of Merlivat and Nief (1967) data, cf. Jouzel $\left(1986\right.$, p. 65)) and $\alpha_{\mathrm{lv}}=1.1123$.

$\dagger$ Calculated from measured $\alpha_{\mathrm{sv}}=1.0152$ and $\alpha_{\mathrm{lv}}=1.0117$. 
our values, but some are lower, which might be due to insufficient stirring of the water.

For ${ }^{18} \mathrm{O}$, the value of O'Neil (1968), based on only two runs, is compatible with ours. Beck and Münnich (personal communication, 1988) recently obtained results in agreement with ours; they found, however, that - especially in salt water - the deuterium fractionation may depend on the growth direction of the ice crystals with respect to the $c$ axis, an hypothesis we cannot test with our results. Craig and Hom (1968) worked with a $\mathrm{NaCl}$ solution of $4 \%$ chlorinity and found $\epsilon_{18}=2.65 \%$. Since they worked with a salt solution, their value is not directly comparable with ours. Our deuterium results are in excellent agreement with those of Posey and Smith (1957) and of Arnason (1969), both of whom took into account the effect of finite freezing rates and obtained the equilibrium value in a similar way to us, and with that of Beck and Münnich (personal communication, 1988), who achieved equilibrium by slow freezing and vigorous stirring.

The "indirect" results in Table 1 are calculated from experimental water-vapour and ice-vapour fractionation factors, as

$$
\mathrm{a}(\text { ice-water })=\alpha(\text { ice-vapour }) /(\text { water-vapour }) \text {. }
$$

The indirect value for ${ }^{18} \mathrm{O}$ is significantly higher, and the one for deuterium lower than our results.

The "theoretical" value in Table 1 was obtained from partition functions, in the same way as by Majoube $(1971 \mathrm{a}, \mathrm{b})$ for the pairs ice-vapour and water-vapour, and using the spectroscopic data compiled by Majoube. The value of 1.00292 is in excellent agreement with our experimental result. This may, however, be somewhat fortuitous, since the vibrational frequencies for ice cannot be defined precisely from spectroscopic data (Majoube, 1971a).

\section{SIGNIFICANCE FOR NATURAL PROCESSES}

During freezing under natural conditions, the ice will not necessarily be formed in isotopic equilibrium with the bulk water, depending on both the freezing rate and the rate of mixing of the water. Souchez and others (1987) made deuterium measurements on ice in a lake and found an apparent fractionation factor $\epsilon_{\text {app }} \approx 12 \%$ (i.e. roughly half the equilibrium value $\epsilon$ ) and a mean freezing velocity of $0.18 \mathrm{~cm} \mathrm{~d}^{-1}$. Following section 3 , this would correspond to a transfer velocity for water mixing $w=v_{\mathrm{f}} /(1-\epsilon \mathrm{app} / \epsilon)=0.42 \mathrm{~cm} \mathrm{~d}^{-1}$. With Danckwerts' (1970) surface renewal model, $w=(\mathrm{D} k)^{\frac{1}{2}}$, so that the corresponding mean residence time of a water parcel at the ice-water interface, $k^{-1}=\mathrm{D} / w^{2}$, would be $4.1 \times 10^{5} \mathrm{~s}=4.8 \mathrm{~d}$. Souchez and others (1987) treated the results with a film model in which transport from the interface is controlled by a stagnant, diffusive layer. Layer thicknesses $z$ of 3 and $4.5 \mathrm{~cm}$ were required to explain the results, which correspond to characteristic diffusion times, given by $z^{2}=2 \mathrm{D} \cdot t$, of $4.5 \times 10^{5} \mathrm{~s}(5.2 \mathrm{~d})$ and $10^{6} \mathrm{~s}$ $(11.7 \mathrm{~d})$. While it is difficult to judge what are reason- able values for the residence time near the interface (or the transfer velocity, or the diffusive film thickness), the times obtained from both models appear unrealistically high. The essential result of the study of Souchez and others is, however, an indication that lake ice may be formed significantly off isotopic equilibrium.

\section{ACKNOWLEDGEMENTS}

We are grateful to K.O. Münnich and C. Junghans, Institute of Environmental Physics, Heidelberg, for analysing $\delta \mathrm{D}$ on our samples. We also thank K. Hänni, who carried out the measurements. Thanks are due to J. Jouzel and K. O. Münnich for constructive comments. This work was supported financially by the Swiss National Science Foundation.

\section{REFERENCES}

Arnason, B. 1969. Equilibrium constant for the fractionation of deuterium between ice and water. J. Phys. Chem., 73(10), 3491-3494.

Craig, H. and B. Hom. 1968. Relationships of D, ${ }^{18} \mathrm{O}$ and chlorinity in the formation of sea ice. Trans. Am. Geophys. Union, 49, 216-217.

Danckwerts, P.V. 1970. Gas liquid reactions. New York, McGraw Hill Book Co.

Gat, J.R. 1980. The isotopes of hydrogen and oxygen in precipitation. In Fritz, P. and J.-C. Fontes, eds. Handbook of environmental isotope geochemistry. Vol. 1. New York, Elsevier, 21-47.

Jouzel, J. 1986. Isotopes in cloud physics: multiphase and multistage condensation processes. In Fritz, P. and J.C. Fontes, eds. Handbook of environmental isotope geochemistry. Vol. 2. Amsterdam, etc., Elsevier, 61112.

Majoube, M. 1971a. Fractionnement en oxygène-18 entre la glace et la vapeur d'eau. J. Chim. Phys., 68, 625636.

Majoube, M. 1971b. Fractionnement en oxygene-18 et en deutèrium entre l'eau et sa vapeur. J. Chim. Phys., 68, 1423-1436.

Merlivat, L. and G. Nief. 1967. Fractionnement isotopique lors des changements d'état solide-vapeur et liquide-vapeur de l'eau à des températures inférieures à $0^{\circ} \mathrm{C}$. Tellus, 19(1), 122-127.

O'Neil, J.R. 1968. Hydrogen and oxygen isotope fractionation between ice and water. J. Phys. Chem., 72(10), 3683-3684.

Posey, C. and A. Smith. 1957. The equilibrium distribution of light and heavy waters in a freezing mixture. J. Am. Chem. Soc., 79, 555-557.

Souchez, R. A., J.-L. Tison and J. Jouzel. 1987. Freczing rate determination by the isotopic composition of the ice. Geophys. Res. Lett., 14(6), 599-602.

Stiefel, E. 1976. Einführung in die numerische Mathematik. Stuttgart, Teubner.

The accuracy of references in the text and in this list is the responsibility of the authors, to whom queries should be addressed. 